\title{
Position and dimensions of the mental foramen and presence of the anterior loop in the Egyptian population: a retrospective CBCT study
}

\author{
M. Shalash ${ }^{1}$, Maram E. Khallaf ${ }^{2^{*}}$ and A. R. Ali ${ }^{3}$
}

\begin{abstract}
Aim: Understanding the mental foramen (MF) position and prevalence and location of the anterior loop (AL) is important during clinical and surgical procedures close to the mental foramen to avoid damage to the neurovascular bundle. The current study was done to determine the location of the MF, its distance from the inferior border of the mandible, and prevalence of AL in Egyptian population using cone beam computed tomography $(\mathrm{CBCT})$.
\end{abstract}

Methods: A retrospective analysis of CBCT images was done in this study. Images of Egyptian patients who have already been subjected to CBCT examination as part of their dental diagnosis and/or treatment planning were included according to the proposed eligibility criteria.

Results: This study showed that the most common location of the MF (43.8\% on the left side and $67.9 \%$ on the right side) is located below the apex of the second premolar. The mean size of mental foramen showed a height of $3.32 \mathrm{~mm}$ in females, $3.60 \mathrm{~mm}$ in males, and a width of $3.41 \mathrm{~mm}$ in females and $3.59 \mathrm{~mm}$ in males. The mean value of distance from inferior border was $10.08 \mathrm{~mm}$ in females and $10.55 \mathrm{~mm}$ in males. Fifty-five percent of the cases showed presence of anterior loop.

Conclusion: These results are consistent with similar radiographic studies regarding size and location of MF and distances between MF and adjacent anatomic structures. The most common position of the MF is below the 2nd premolar. AL was found in more than half of the cases examined.

Keywords: Mental foramen, Anterior loop, Inferior alveolar canal, Dental implant, Periapical surgery

\section{Introduction}

The MF is a channel-like opening that is narrow at the base and wide at the top through which the mental nerve exits the mental canal (Phillips et al. 1990). It is important to be aware of the position of the MF during clinical procedures such as elevation of mucoperiosteal flaps, local anesthesia injection, and any bone surgery being performed in the vicinity of the MF. During

\footnotetext{
* Correspondence: maram_3@yahoo.com

${ }^{2}$ Restorative and Dental Materials Department, National Research Centre, Cairo, Egypt

Full list of author information is available at the end of the article
}

surgical procedures close to the MF such as the placement of endo-osseous implants, root end surgery, surgical removal of impacted teeth, cysts, and tumors, the operator must avoid injuring the neurovascular bundle exiting through the MF. Although it has been recommended that a safe distance of $2 \mathrm{~mm}$ should be kept between endo-osseous implants and the MF, some studies have reported altered sensation in the area supplied by the mental nerve following their placement (Bartling et al. 1999; Wismeijer et al. 1997; Walton 2000).

The part of inferior alveolar nerve (IAN) presents anterior to the MF, before leaving the canal is known as 
the anterior loop (AL) of the IAN (Apostolakis and Brown 2012). Prevalence and location of the AL is also important during different surgical procedures, especially during placing dental implants in fully edentulous patients. A study comparing the dissection of the AL anatomically and CBCT scans of cadaver specimens showed almost near equal measurements, from which the authors concluded that $\mathrm{CBCT}$ is considered reliable in determining the extent of the AL (Uchida et al. 2009).

The exact location of MF is important for both diagnostic and clinical purposes.

As for diagnosis, MF can be mistaken for a pathology near the apices of the premolar teeth. From a clinical aspect, knowing precisely the exact location of the nerve and presence/absence of $\mathrm{AL}$ is paramount to prevent any nerve injury with its postoperative sequala (Ngeow and Yuzawati 2003). It was previously stated that the MF most common position is below the apex of second premolar (Fabian 2007) or between the apices of first and second premolar (Al Jasser and Nwoku 1998). The MF position is influenced by ethnic background, gender, age, tooth loss, and subsequent ridge resorption (Igbigbi and Lebona 2005). Literature shows that the length of AL may vary among different groups of the population (Apostolakis and Brown 2012; Chen et al. 2013; Lu et al. 2015).

Injury to the mental nerve can cause sensory disturbance in the lower lip, skin, and surrounding mucosa (Greenstein and Tarnow 2006; Ritter et al. 2012), and temporary or permanent neurosensory following surgical placement of endo-osseous implants have been reported (Bartling et al. 1999; Walton 2000).

To accurately locate the MF and AL, various techniques have been suggested. This includes manual detection, direct inspection during surgery, panoramic or periapical radiographs, magnetic resonance imaging (MRI), computed tomography (CT), and cone beam computed tomography (CBCT). Most of these methods have limitations such as cost, excess radiation, and magnification (Aminoshariae et al. 2014).
High-resolution CBCT is considered one of the most promising and precise techniques present that can accurately determine the position of MF and presence of AL (Vujanovic-Eskenazi et al. 2015).

To the knowledge of the authors, no previous study has mentioned the location of MF and prevalence of AL among Egyptians using CBCT; hence, the present study was done to determine the position of MF and its relationship to neighboring teeth and prevalence of $\mathrm{AL}$ in the Egyptian population using CBCT.

\section{Materials and methods}

A retrospective analysis of $\mathrm{CBCT}$ was done in this study. CBCTs were taken in a private radiology centre (ORASCAN Oral \& Maxillofacial Imaging Centre) located in Cairo, Egypt. Being a retrospective study, CBCT images of Egyptian patients who have already been subjected to CBCT examination as part of their dental diagnosis and/or treatment planning during the years 2017 till 2019 were included according to the proposed eligibility criteria. Based on sample size calculation, a sample of 120 scans was selected randomly between the scans that met the eligibility criteria. CBCT images of mandible quadrants belonging to Egyptian individuals were included in this study.

\section{Inclusion criteria of CBCT images}

- Only ethnic Egyptian population.

- Clear view of MF area including lower, upper, lingual, and buccal borders of the mandible.

- Adjacent permanent teeth from canine to first molar are present.

\section{Exclusion criteria}

- Presence of mixed dentition.

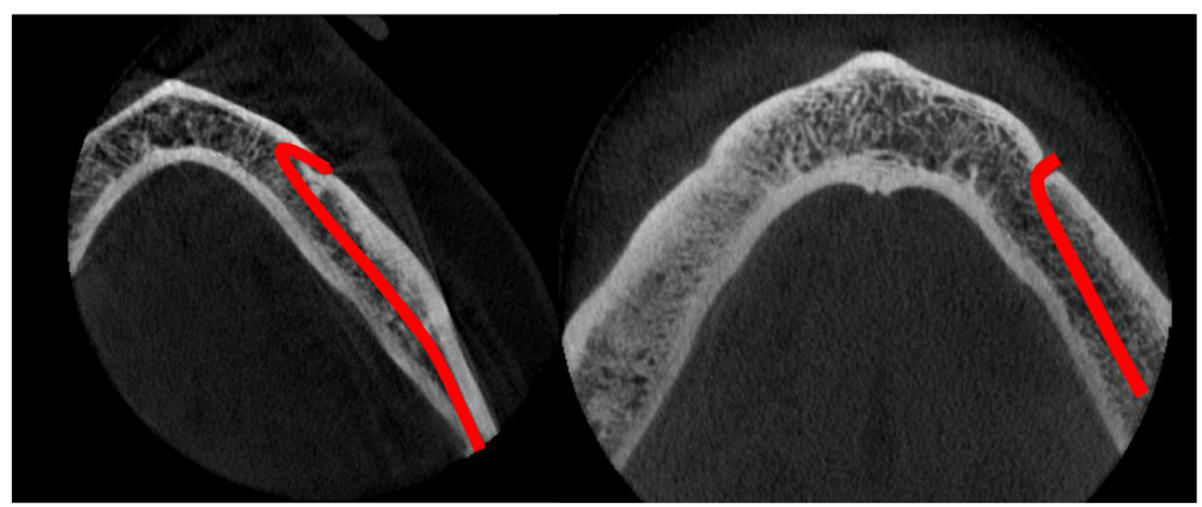

Fig. 1 Modified axial images showing presence of anterior loop (left) and absence of anterior loop (right) 


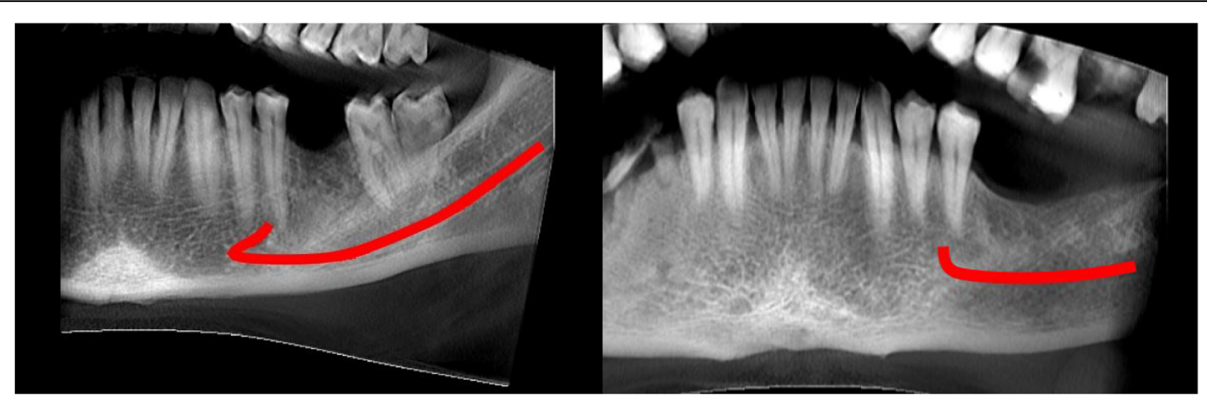

Fig. 2 Reconstructed panoramic view showing presence of anterior loop (left) and absence of anterior loop (right)

- Presence of any radiolucent or radiopaque lesion obscuring the MF.

Retrospective data analysis was performed after the CBCT images are pooled from the computer database. Using Cranex ${ }^{\circ}$ 3DX (SOREDEX, Finland), exposure parameters used were 0.2 voxel resolution, $8 \times 6 \mathrm{~cm}$ FOV, 90 $\mathrm{kVp}, 10 \mathrm{~mA}$, and $6 \mathrm{~s}$ exposure time, and CBCT images were analyzed using OnDemand3D * app (Cybermed, Seoul, Korea); using the 3D module, reference lines were modified to confine with the buccolingual orientation of the inferior alveolar loop, to obtain a modified axial cut showing the anterior loop of the inferior alveolar nerve (if present) and mental foramen opening on the same plane (Figs. 1 and 2).

On the modified sagittal plane, the width of the mental foramen was measured, and the distance between the inferior margin of the mental foramen and the inferior border of the mandible was obtained (Fig. 3); the vertical length of the mental foramen was also measured on the modified cross-sectional images.

\section{Statistical analysis}

Data were analyzed using the Statistical Package for the Social Sciences (SPSS-19.0) software package (IBM, Chicago, USA).

Descriptive statistics was utilized for acquiring the position of MF, presence of $\mathrm{AL}$, and distance between MF and inferior border of the mandible. It was also applied for frequency analysis of the distance between MF and mandibular border.

\section{Results}

\section{Position of mental foramen}

The MF position with reference to the neighboring teeth on the left side of the mandible is shown in Table 1. Four cases (6.3\%) of the MF were found below the apex of 1 st premolar $($ male $=100 \%$, female $=0 \%$; ; whereas in 20 cases $(31.3 \%)$, the MF was located between the 1st and 2nd premolars (male $=8(40 \%)$, female $=12(60 \%)$. In 28 cases (43.8\%), the MF was located below the apex of 2 nd premolar $($ male $=10(35.7 \%)$, female $=18$

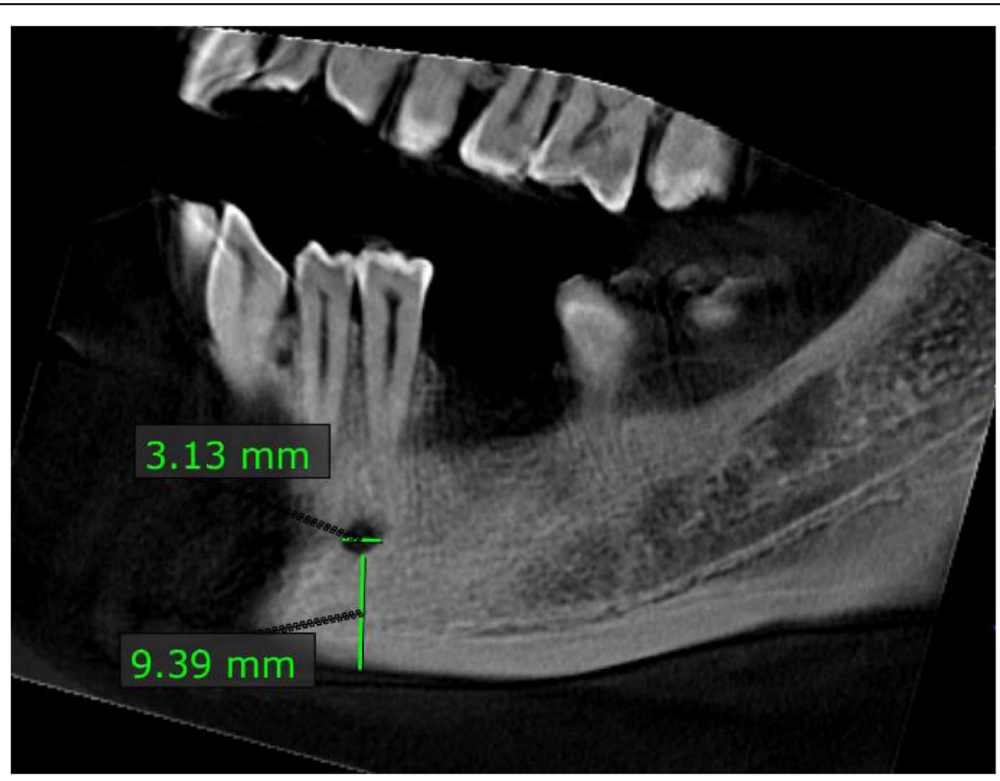

Fig. 3 Modified sagittal image showing measurement of the width as well as distance of the MF from the inferior border of the mandible 
Table 1 Position of MF in relation to gender and adjacent teeth on the left side of mandible

\begin{tabular}{|c|c|c|c|c|}
\hline \multirow[t]{3}{*}{ Variables } & \multicolumn{4}{|c|}{$\begin{array}{l}\text { Position of mental foramen } \\
\text { (left side) }\end{array}$} \\
\hline & \multicolumn{2}{|c|}{ Female } & \multicolumn{2}{|c|}{ Male } \\
\hline & $\bar{n}$ & $\%$ & $\bar{n}$ & $\%$ \\
\hline Below 1st premolar & 0 & $0 \%$ & 4 & $100 \%$ \\
\hline Between 1st and 2nd premolar & 12 & $60 \%$ & 8 & $40 \%$ \\
\hline Below 2nd premolar & 18 & $64.3 \%$ & 10 & $35.7 \%$ \\
\hline Between 2nd premolar and 1st molar & 4 & $40 \%$ & 6 & $60 \%$ \\
\hline Below 1st molar & 0 & $0 \%$ & 2 & $100 \%$ \\
\hline
\end{tabular}

(64.3\%)). Ten cases (15.6\%) showed the position of MF between 2nd premolar and 1st molar (male $=6(60 \%)$, female $=4(40 \%)$ ) while 2 cases (3.1\%) showed position of MF below the apex of 1 st molar $($ male $=100 \%$, Female $=0 \%$ ).

The position of the MF in relation to the neighboring teeth on the right side of the mandible is shown in Table 2. Two cases $(3.6 \%)$ of MF were positioned below the apex of 1st premolar $($ male $=0 \%$, female $=100 \%$ ), whereas 12 cases (21.4\%) showed the MF between 1st and 2nd premolars $($ male $=4(33.3 \%)$, female $=8(66.7 \%))$, and 38 cases $(67.9 \%)$ of the MF were located below the apex of 2nd premolar $($ male $=14(36.8 \%)$, female $=24(63.2 \%))$. Four cases $(7.1 \%)$ of the position of MF were between the 2nd premolar and 1st molar $($ male $=0 \%$, female $=100 \%)$ while 0 cases $(0 \%)$ showed position of MF below the apex of 1st molar.

\section{Size of mental foramen and distance from the inferior border}

The mean size of mental foramen showed a height of 3.32 $\mathrm{mm}$ in females, $3.60 \mathrm{~mm}$ in males, and a width of $3.41 \mathrm{~mm}$ in females and $3.59 \mathrm{~mm}$ in males. The mean value of distance from inferior border was $10.08 \mathrm{~mm}$ in females and $10.55 \mathrm{~mm}$ in males with no significance difference between both genders. While regardless of gender, the mean height and width of the mental foramen are $3.43 \mathrm{~mm}$ and 3.49 $\mathrm{mm}$ respectively. Regarding the mean distance from the inferior border irrespective of gender, it was found to be $10.27 \mathrm{~mm}$ (Tables 3 and 4).

Table 2 Position of mental foramen in relation to gender and adjacent teeth on right side of mandible

\begin{tabular}{|c|c|c|c|c|}
\hline \multirow[t]{3}{*}{ Variables } & \multicolumn{4}{|c|}{$\begin{array}{l}\text { Position of mental foramen } \\
\text { (right side) }\end{array}$} \\
\hline & \multicolumn{2}{|c|}{ Female } & \multicolumn{2}{|c|}{ Male } \\
\hline & $n$ & $\%$ & $n$ & $\%$ \\
\hline Below 1st premolar & 2 & $100 \%$ & 0 & $0 \%$ \\
\hline Between 1st and 2nd premolar & 8 & $66.7 \%$ & 4 & $33.3 \%$ \\
\hline Below 2nd premolar & 24 & $63.2 \%$ & 14 & $36.8 \%$ \\
\hline Between 2nd premolar and 1st molar & 4 & $100 \%$ & 0 & $0 \%$ \\
\hline Below 1st molar & 0 & $0 \%$ & 0 & $0 \%$ \\
\hline
\end{tabular}

Table 3 Properties of mental foramen irrespective of gender

\begin{tabular}{lll}
\hline Variables & Properties & \\
\cline { 2 - 3 } & Mean & SD/\% \\
\hline Distance from inferior border & 10.27 & 1.69 \\
Height & 3.43 & 1.11 \\
Width & 3.49 & 0.93 \\
\hline
\end{tabular}

\section{Presence of $A L$}

Regarding the presence of the anterior loop, 66 (55\%) showed the presence of a loop while 54 (45\%) had no loop with no significant difference between gender (Fig. 4).

\section{Discussion}

The current study was aimed to detect the exact position of the MF and presence or absence of anterior loop using cone beam computer tomography in Egyptian population. Proper determination of the location of MF is mandatory for local anesthetic procedures as well as for several oral surgical procedures to avoid serious complications (Greenstein and Tarnow 2006). Literature is scarce for this type of studies in the Egyptian population; thus, comparisons were done in relation to different populations.

Studies varied in locating the position of MF; some studies stated that the most common location is between 1st and 2nd premolars. Differences exist in the location of MF among different ethnic groups. Previous studies have shown that the MF is commonly found between 1st and 2nd premolars (Gungor et al. 2006; Von Arx et al. 2013; Verma et al. 2015; Currie et al. 2016). Some studies on the Saudi population found out that the MF is most commonly located below the 2nd premolar (Al Jasser and Nwoku 1998; Al-Mahalawy et al. 2017). Our results showed the same where $43.8 \%$ of the scans are on the left side and $67.9 \%$ of the scans are on the right side, and the MF was located below the 2nd premolar. Variation between studies may be due to different methods of evaluation, and studies carried out on CBCT are considered to be more accurate and give more details about the exact location over studies carried out on panoramic x-rays.

In our study, the MF was present on average 10.27 $\mathrm{mm}$ above the lower border of the mandible. In 386 CBCT scans, Kalender et al. (Kalender et al. 2012) found the MF to be $12.4 \mathrm{~mm}$ above the lower border. It is

Table 4 Properties of mental foramen

\begin{tabular}{|c|c|c|c|c|c|}
\hline \multirow[t]{3}{*}{ Variables } & \multicolumn{4}{|c|}{ Gender } & \multirow{3}{*}{$P$ value } \\
\hline & \multicolumn{2}{|c|}{ Female } & \multicolumn{2}{|l|}{ Male } & \\
\hline & Mean & $\% / S D$ & Mean & $\% / S D$ & \\
\hline Distance from inferior border & 10.08 & 1.64 & 10.55 & 1.76 & 0.156 \\
\hline Height & 3.32 & 0.88 & 3.60 & 1.39 & 0.17 \\
\hline Width & 3.41 & 0.85 & 3.59 & 1.04 & 0.21 \\
\hline
\end{tabular}




\section{Properties}

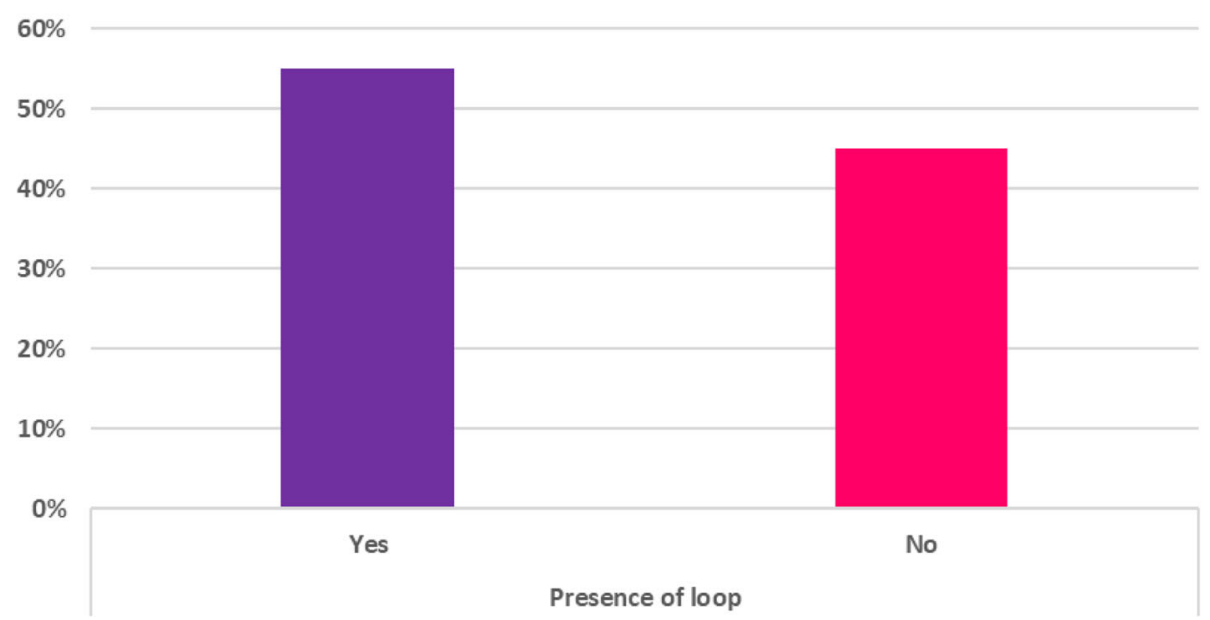

Fig. 4 Bar chart representing presence of anterior loop

worth mentioning that studies with longer distance between mental foramen and inferior border of the mandible used the center of the MF and not the inferior margin of the MF as the initial point of measurement (Gupta 2008; Guo et al. 2009; Neiva et al. 2004; Agthong et al. 2005).

Position of the MF in relation to inferior border of the mandible or in relation to adjacent teeth carries important clinical implications including prevention of mental nerve injury during oral surgical procedures in this region such as cyst inoculation, apical root end surgery at mandibular premolar area, surgical extraction of impacted teeth, fixation of mandibular fractures, and placement of endo-osseous implants. Additionally, knowledge about the precise position of the MF can lead to more accurate and more profound local anesthesia (Iyengar et al. 2013).

The presence of the AL of the mandibular canal is a very interesting topic, especially when endo-osseous implant placement is planned in the anterior mandible. Previous studies on cadavers reported conflicting results regarding presence of AL. Some studies reported high frequency of $\mathrm{AL}$, and these studies were questioned as identification of the AL that was done by insertion of a probe through the MF. This method of identification is not accurate as the probe might be inserted into the anterior continuation of the mandibular canal, i.e., into the mandibular incisive canal.

In the present study, $55 \%$ of the cases showed a presence of an AL, where it was found insignificantly more in males than females. Von Arx has reported presence of AL in $70.1 \%$ of the cases (Von Arx et al. 2013). Uchida et al. also reported presence of AL in $71 \%$ of Japanese cadaver hemi mandibles (Uchida et al. 2009). De
Oliveira-Santos et al. (De Oliveira-Santos et al. 2012) assessed $100 \mathrm{CBCT}$ bilaterally and showed less prevalence of an AL (22\%) in axial images. They also reported that the AL was not clearly distinguishable in $11 \%$ of cross sections and in 5\% of panoramic views. Their conclusion was that identifying the mental canal from surrounding medullary spaces was quite difficult. This might explain the difference between our study and other studies that reported higher or lower frequencies of AL. Also, different studies were performed on different ethnic groups, thus, it could cause variations of the results.

Regarding the size of the mental foramen, the mean height was $3.43 \mathrm{~mm}$, and the mean length was 3.49 $\mathrm{mm}$; these are close to the results of another CBCT study by Kalender et al. (Kalender et al. 2012). However, in our study, there was no significant difference between both genders on the contrary to Kalender et al. who found that males had significantly larger MF than females.

\section{Conclusion}

The results of this study are consistent with similar radiographic studies regarding size and position of MF and distances between MF and adjacent important anatomic structures. The most common position of the MF is below the 2nd premolar. The anatomic position of the MF must be considered during oral surgical procedures in the premolar area. In $55 \%$ of the cases, $\mathrm{AL}$ was present in the axial plane.

\section{Abbreviations}

MF: Mental foramen; AL: Anterior loop; CBCT: Cone beam computed tomography; IAN: Inferior alveolar nerve; CT: Computed tomography; MRI: Magnetic resonance imaging 


\section{Acknowledgements}

Not applicable

\section{Authors' contributions}

MS analyzed the CBCT images, collected the data, and helped to draft the manuscript. MK drafted the manuscript, collected the data, and designed the study. AA performed the CBCT imaging and analyzed the CBCT images. All authors read and approved the final manuscript.

\section{Funding}

No funding.

\section{Availability of data and materials}

All data generated or analyzed during this study are included in this published article.

\section{Ethics approval and consent to participate}

Not applicable

\section{Consent for publication}

Not applicable

\section{Competing interests}

The authors declare that they have no competing interests.

\section{Author details}

'Surgery and Oral Medicine Department, National Research Centre, Cairo, Egypt. ${ }^{2}$ Restorative and Dental Materials Department, National Research Centre, Cairo, Egypt. ${ }^{3}$ OraScan Radiology Centre, Cairo, Egypt.

Received: 18 April 2020 Accepted: 16 June 2020

Published online: 02 July 2020

\section{References}

Agthong S, Huanmanop T, Chentanez V (2005) Anatomical variations of the supraorbital, infraorbital, and mental foramina related to gender and side. J Oral Maxillofac Surg 63:800-804

Al Jasser NM, Nwoku AL (1998) Radiographic study of the mental foramen in a selected Saudi population. Dentomaxillo Radiol 27(6):341-343

Al-Mahalawy H, Al-Aithan H, Al-Kari B, Al-Jandan B, Shujaat S (2017) Determination of the position of mental foramen and frequency of anterior loop in Saudi population. A retrospective CBCT study. Saudi Dent J 29(1):2935

Aminoshariae A, Su A, Kulild JC (2014) Determination of the location of the mental foramen: a critical review. J Endod 40(4):471-475

Apostolakis D, Brown JE (2012) The anterior loop of the inferior alveolar nerve: prevalence, measurement of its length and a recommendation for interforaminal implant installation based on cone beam CT imaging. Clin Oral Implants Res 23(9):1022-1030

Bartling R, Freeman K, Kraut RA (1999) The incidence of altered sensation of the mental nerve after mandibular implant placement. J Oral Maxillofac Surg 57: 1408-1412

Chen JCH, Lin LM, Geist JR, Chen JY, Chen CH, Chen YK (2013) A retrospective comparison of the location and diameter of the inferior alveolar canal at the mental foramen and length of the anterior loop between American and Taiwanese cohorts using CBCT. Surg Radiol Anat 35(1):11-18

Currie CC, Meechan JG, Whitworth JM, Carr A, Corbett IP (2016) Determination of the mental foramen position in dental radiographs in 18-30 year olds. Dentomaxillo Radiol 45(1):20150195

De Oliveira-Santos C, Souza PH, de Azambuja B-CS et al (2012) Assessment of variations of the mandibular canal through cone beam computed tomography. Clin Oral Investig 16:387-393

Fabian FM (2007) Position, shape and direction of opening of the mental foramen in dry mandibles of Tanzanian adult black males. Ital J Anat Embryol 112(3):169-177

Greenstein G, Tarnow D (2006) The mental foramen and nerve: clinical and anatomical factors related to dental implant placement-a literature review. J Periodontol 77:1933-1943

Gungor K, Ozturk M, Semiz M, Lynn Brooks S (2006) A radiographic study of location of mental foramen in a selected Turkish population on panoramic radiograph. Collegium Antropo- logicum 30(4):801-805
Guo JL, Su L, Zhao JL et al (2009) Location of mental foramen based on soft- and hard- tissue landmarks in a Chinese population. J Craniofac Surg 20:22352237

Gupta T (2008) Localization of important facial foramina encountered in maxillofacial surgery. Clin Anat 21:633-640

Igbigbi PS, Lebona S (2005) The position and dimensions of the mental foramen in adult Malawian mandibles. West Afr J Med 24(3):184-189

lyengar AR, Patil S, Nagesh KS, Mehkri S, Manchanda A (2013) Detection of anterior loop and other patterns of entry of mental nerve into the mental foramen: a radiographic study in panoramic images. J Dental Implants 3(1): $21-25$

Kalender A, Orhan K, Aksoy U (2012) Evaluation of the mental foramen and accessory mental foramen in Turkish patients using cone-beam computed tomography images reconstructed from a volumetric rendering program. Clin Anat 25:584-592

Lu Cl, Won J, Al-Ardah A, Santana R, Rice D, Lozada J (2015) Assessment of the anterior loop of the mental nerve using cone beam computerized tomography scan. J Oral Implantol 41(6):632-639

Neiva RF, Gapski R, Wang HL (2004) Morphometric analysis of implant-related anatomy in Caucasian skulls. J Periodontol 75:1061-1067

Ngeow WC, Yuzawati Y (2003) The location of the mental foramen in a selected Malay population. J Oral Sci 45(3):171-175

Phillips JL, Weller RN, Kulild JC (1990) The mental foramen: Part I. Size, orientation, and positional relationship to the mandibular second premolar. J Endod 16(5):221-223

Ritter L, Neugebauer J, Mischkowski RA, Dreiseidler T, Rothamel D, Richter U, Zinser MJ, Zoller JE (2012) Evaluation of the course of the inferior alveolar nerve in the mental foramen by cone beam computed tomography. Int J Oral Maxillofac Implants 27(5):1014-1021

Uchida Y, Noguchi N, Goto M et al (2009) Measurement of anterior loop length for the mandibular canal and diameter of the mandibular incisive canal to avoid nerve damage when installing endosseous implants in the interforaminal region: a second attempt introducing cone beam computed tomography. J Oral Maxillofac Surg 67:744-750

Verma P, Bansal N, Khosa R, Verma KG, Sachdev SK, Patwardhan N, Garg S (2015) Correlation of radiographic mental foramen position and occlusion in three different Indian populations. West Indian Med J 64(3):269-274

Von Arx T, Friedli M, Sendi P, Lozanoff S, Bornstein MM (2013) Location and dimensions of the mental foramen: a radiographic analysis by using conebeam computed tomography. J Endod 39(12):1522-1528

Vujanovic-Eskenazi A, Valero-James JM, Sanchez-Garces MA, Gay-Escoda C (2015) A retrospective radiographic evaluation of the anterior loop of the mental nerve: comparison between panoramic radiography and cone beam computerized tomography. Med Oral Patol Oral Cir Bucal 20(2):239

Walton JN (2000) Altered sensation associated with implants in the anterior mandible: a prospective study. J Prosthet Dent 83:443-449

Wismeijer D, van Waas MA, Vermeeren Jl, Kalk W (1997) Patients' perception of sensory disturbances of the mental nerve before and after implant surgery: a prospective study of 110 patients. Br J Oral Maxillofac Surg 35:254-259

\section{Publisher's Note}

Springer Nature remains neutral with regard to jurisdictional claims in published maps and institutional affiliations.

\section{Submit your manuscript to a SpringerOpen ${ }^{\circ}$ journal and benefit from:}

- Convenient online submission

- Rigorous peer review

- Open access: articles freely available online

- High visibility within the field

- Retaining the copyright to your article

Submit your next manuscript at $\boldsymbol{\nabla}$ springeropen.com 